\title{
AOR
}

Selected Papers of \#AolR2021:

The 22nd Annual Conference of the

Association of Internet Researchers

Virtual Event / 13-16 Oct 2021

\section{SOCIAL MEDIA LOGIC AND HEALTH COMMUNICATION BETWEEN INDEPENDENCE AND CONSTRAINTS: EVIDENCE FROM ITALY DURING THE COVID-19 PANDEMIC}

\author{
Elisabetta Locatelli \\ Università Cattolica del Sacro Cuore, Italy
}

Alessandro Lovari

Università di Cagliari, Italy

\section{Theoretical Framework}

During the latest years, public health organizations have faced the pressures of digitization adopting new means of communication, especially social media, to timely deliver information and constantly relate with their publics (Shi et al., 2016), entering the phase defined as "Medicine 2.0" and "Health 2.0" (Eysenbach, 2008; van De Belt et al., 2010). The Covid-19 pandemic impacted on this ongoing process characterized also by the necessity to capillary spread reliable information about the virus and the measures for preventing its diffusion (Lovari, 2020). In this perspective, social media can represent an opportunity for public health organizations, but also a risk, due to their algorithmic logics and limits of access that can reiterate disparities and inequalities (Van Dijck \& Poell, 2013; Gillespie, 2010) as pointed out also by critical digital health studies (Lupton, 2018).

In this paper an original approach was implemented, hybridizing health communication and social media studies. This approach is fruitful because it offers the possibility to understand both the evolution of public health communication and the role of social media platforms, an area partially investigated by the scientific literature, critically arguing about the pervasive role of digital and social media in the field of health communication, magnified during the Covid-19 pandemic.

Italy was the first Western country affected by the Covid-19 pandemic and the initial outbreaks were discovered in Lombardy (North of Italy). By the end of February 2020, the country entered in an emergency with local and national lockdowns, limited access to hospitals in some areas due to the heavy presence of Covid-19 patients, and a 
cacophony of voices stemming from an informative crisis that have characterized Italy by the last decade (Lovari et al., 2020).

This paper presents the results of a study that investigated how a sample of 13 local health authorities (LHAs), located in the areas of Lombardy mostly impacted by Covid19 , faced the pandemic through the communication on their official Facebook pages during the early weeks of the emergency (January-March 2020).

\section{Methodology}

After having identified the sample of the 13 LHAs, researchers retrieved Facebook posts from official pages for the period January-March 2020, using Fanpage Karma. The dataset, exported in an Excel 2020 file, was manually cleaned from duplicated entries, thus composing a final dataset of 1674 Facebook messages.

A qualitative coding of the posts was carried out, following a coding scheme developed according to the theoretical framework adopted. Among the variables considered there were: the quantitative dimension of the posting, connected to the logics of

programmability and popularity (Van Dijck \& Poell, 2013), including the number of posts, users' total interactions and the engagement rate (Cazorla Milla et al., 2020); the content of the posts, according to previous categorization of social media health communication (Cioni \& Lovari, 2014).

\section{Main Results}

The study showed the interdependence between LHAs and social media communication during the early phase of the Covid-19 pandemic and that the logics of programmability and popularity (Van Dijck \& Poell, 2013) were particularly stressed. Data highlighted in fact that the number of posts has increased during the period of analysis (January 300 posts; February 490 posts; March 884 posts) and that LHAs flexibly adapted the editorial plans according to the situation $(66.01 \%, \mathrm{~N}=1105$ posts Covid-19 related, $33.99 \%, \mathrm{~N}=569$ of the posts not Covid-19 related). Peaks in the number of posts corresponded with the pivotal moments of the pandemic (the discovery of the "patient one" and the regional and national lockdown). Although it could be expected, it was not taken for granted that social media communication would become pivotal during the early phase of the emergency. On the one side this can be interpreted as an opportunity for LHAs to communicate with stakeholders and laypeople, when other means of communication (like face-to-face meetings) were not accessible. On the other side, social media platforms shaped health communication, pushing LHAs to adapt their institutional languages to the styles of social media communication. The analysis showed indeed a diffuse use of hashtags $(46.12 \%, \mathrm{~N}=772)$ and of visual contents within the messages $(89.72 \%, \mathrm{~N}=1502)$. About the logic of popularity, data highlighted also an increase of the total page likes and of the engagement rate (ER) of the posts (average ER for Covid-19 related posts $0.27 \%$, for other posts $0.07 \%$ ), showing the relevance of contents for citizens. This is highlighted especially by the high number of shares, that contributed to increase the visibility of posts according to the algorithmic logics of the Facebook newsfeed (Facebook, n.d.). LHAs become trustful sources for citizens, sharing also epidemiological data and daily press conferences 
about the evolution of the pandemic $(6,24 \%, N=69)$. For doing this they show also a high degree of connectivity because one third of the posts shared national or regional campaigns $(31.18 \%, \mathrm{~N}=522)$. A key factor, under this point of view, is the low presence of posts dedicated to fake news $(2.53 \%, \mathrm{~N}=28)$, even if they had a high engagement rate $(0.52 \%)$. This result pinpoints that the topic of fake news at that stage of the pandemic was more relevant for citizens, that hugely interacted with them, than for LHAs. Several messages $(32.04 \%, N=354)$ dealt with the theme of citizens' empowerment in order to diffuse correct behaviours for preventing the spreading of the virus, having a lower engagement rate $(0.12 \%)$. This can be interpreted as a result of the flattening effect of their number but also a signal of a different perception of the relevance of the topics for LHAs and users, but it is worthy of further research, in order to understand the dynamics of the platformization of healthcare communication and the role of platforms in the processes of content distribution. The act of engaging with the contents can be interpreted also as the ability of posts to put themes in the users' agenda.

In sum, LHAs' Facebook pages become communicative hubs, acting as complementors within the ecology of platformization (Van Dijck, Poell \& De Waal, 2018) bypassing the intermediation of news media in delivering information. From a public institution point of view, the platformization of healthcare communication can be problematic, since social media don't reach all the targets and also contents diffusion is subject to algorithmic logics. Moreover, LHAs should resist to these logics, pursuing their public role and defining autonomously their content agenda (Lovari \& Locatelli, in press).

This study contributes to the knowledge of the field, showing the relevance of the topic and the fruitfulness of employing an interdisciplinary theoretical framework.

\section{References}

Cazorla Milla, A., Mataruna-Dos-Santos, L.J., \& Muñoz Helú, H. (2020). Content Strategy and Fan Engagement in Social Media. Annals of Applied Sport Science, 8(3), 1-12. https://doi.org/10.29252/aassjournal.905.

Cioni, E., \& Lovari, A. (2014). Social media for health communication: Implementation issues and challenges for Italian public health authorities. In M. Househ, E. Borycki, A. Kushniruk (eds.), Social media and mobile technologies for healthcare (pp. 237-263), Hershey (US): IGI Global.

Eysenbach, G. (2008). Medicine 2.0: social networking, collaboration, participation, apomediation, and openness. Journal of Medical Internet Research, 10(3):e22, 1-9.

Facebook (n.d.), News Feed, https://www.facebook.com/formedia/solutions/news-feed, [retrieved 04/14/2021].

Gillespie, T. (2010). The politics of "platforms". New Media and Society, 12(3), 347-364. https://doi.org/10.1177/1461444809342738.

Guidry, J.P.D., Jin, Y., Orr, C.A., Messner, M., \& Meganck, S. (2017). 'Ebola on Instagram and Twitter'. Public Relations Review, 43(3), 477-486. 
Locatelli, E, Lovari, A. (in press), 'Platformization of healthcare communication. Insights from the early stage of the Covid-19 pandemic in Italy'. Catalan Journal of Communication and Cultural Studies.

Lovari, A. (2020). 'Spreading (dis)trust. Covid-19 misinformation and government intervention in Italy'. Media and Communication. 8(2), 458-461. DOI:

10.17645/mac.v8i2.3219.

Lupton (2018). Digital Health. Critical and Cross-Disciplinary Perspectives, London: Routledge.

Shi J., Poorisat T., \& Salmon C.T. (2016), 'The use of social networking sites (SNS) in health communication campaigns: review and recommendations', Health Communication, 33(1), 49-56.

Van De Belt T.H., Engelen L.J., Berben S.A., \& Schoonhoven L. (2010), 'Definition of Health 2.0 and Medicine 2.0: A systematic review', Journal of Medical Internet Research, 12(2), e18.

Van Dijck, J., \& Poell, T. (2013). 'Understanding Social Media Logic'. Media and Communication, 1(1), 2-14. https://doi.org/10.12924/mac2013.01010002.

Van Dijck, José, Thomas, Poell and Martijn, De Waal (2018), The Platform Society: Public Values in a Connective World, New York: Oxford University Press. 